\title{
The integration of traction equipment into a vehicle computer network
}

\author{
V. Rădulescu, I. Străinescu, E. Tudor, F. Bozaș, A. Dascălu \\ \& D. Brăslașu \\ ICPE SAERP SA, Romania
}

\begin{abstract}
The development of on-board electronics of vehicles is related to the evolution of microcontrollers and microprocessor, both in hardware and software issues. Traction equipment has been based on such electronic controllers for decades, but most of the systems are paralleled and have fewer interconnections. The specialists of ICPE SAERP have accomplished the interconnection task on our latest products designed to be operated on trolley buses, trams, light metros or EMU. This working paper presents the interconnection of traction equipment mounted on the Irisbus body and the same communication protocol applied for trams, thus allowing the vehicle to have full on-line diagnosis within the intelligent and advanced transport systems.
\end{abstract}

Keywords: traction, trolley, tram, EMU, controller, microcontroller.

\section{Introduction}

In the last couple of years, a campaign was started in electrical railway transportation to use the equipment on the vehicles to send important data between the wagons along the train and between the train and the train monitoring facilities including using GPS satellites, as shown in the next paragraph.

In order to limit the cost of rerunning old tests, many providers of critical safety systems have started using tools to automate the unit tests. For efficient operation, it is desirable that an automated framework for system testing should be able to serve both in a hardware set-up which is as close as possible to the environment where the product shall operate, and in a pure software set-up, where most of the development is done [1]. The trend towards higher speed, 
more frequent traffic and many traffic operators requires new strategies and solutions for efficient train traffic control and utilization of track capacity [2].

Analyzing the trend of automatic data transfer on high speed trains with modern equipment manufactured by renowned companies, ICPE SAERP began a similar campaign 4 years ago using the equipment on trolleys, trams and light metro in Bucharest. This paper presents the results obtained with equipment mounted on refurbished trams and a few trolleys currently in exploitation in Bucharest, Cluj and Timisoara.

\section{Description of the traction equipment produced by SAERP}

The traction equipment produced by ICPE SAERP is based on the microcontroller electronic units, interconnected via serial link. The serial link used is based on the RS485 standard or on the CAN-bus standard. When critical conditions apply, we are using a separated control bus, thus leaving the diagnosis bus opened for variations of the performed tasks. The control bus is not subject for external diagnosis devices (such portable PC and diagnosis display).

Control commands are based on a Master-Slave architecture, where the Master controller sends group messages containing commands and statuses, while the Slave controllers reply with statuses and measured variables, in a predictable order.

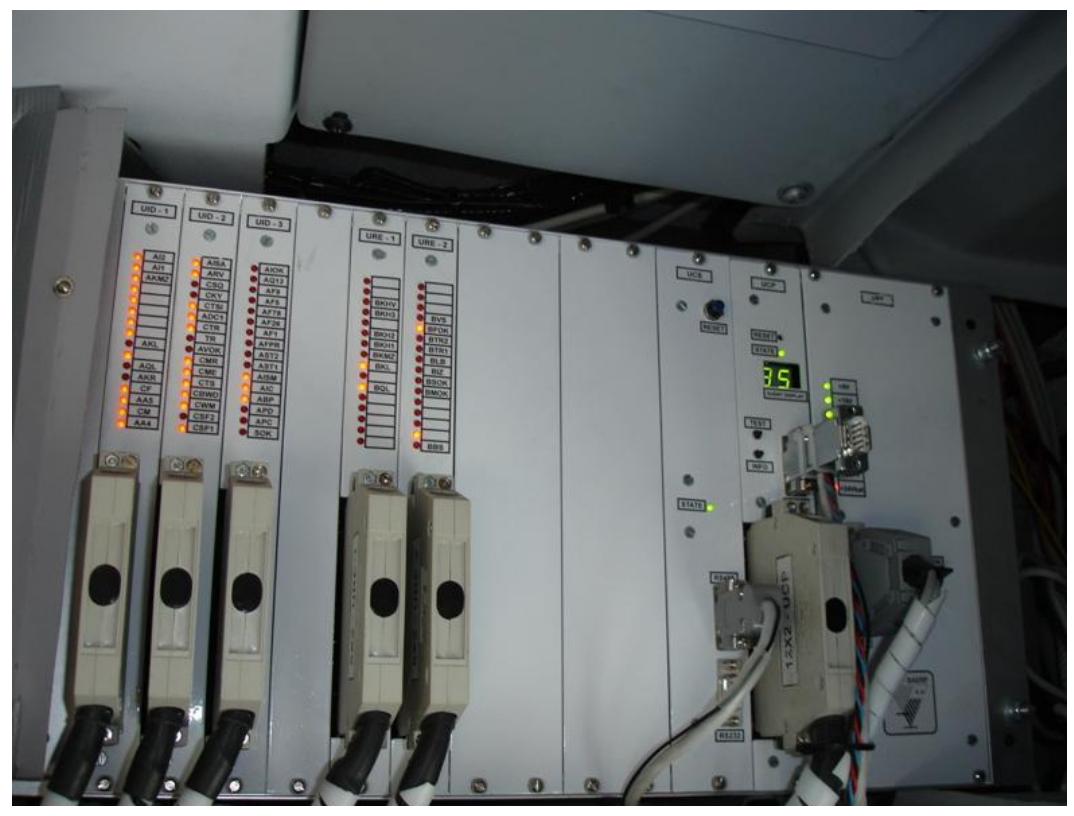

Figure 1: Trolley bus control unit. 
The reply order for the command is aligned with a master's message called a "beacon", with used values of 8 or 16 messages. Each slave controller is programmed to reply at a specific location of the "beacon".

The master controller type SATREC-MMA (figure 1) is located near the driver's desk, and is the main interface for the input commands. The status of the inputs is clearly signalized by individual LED.

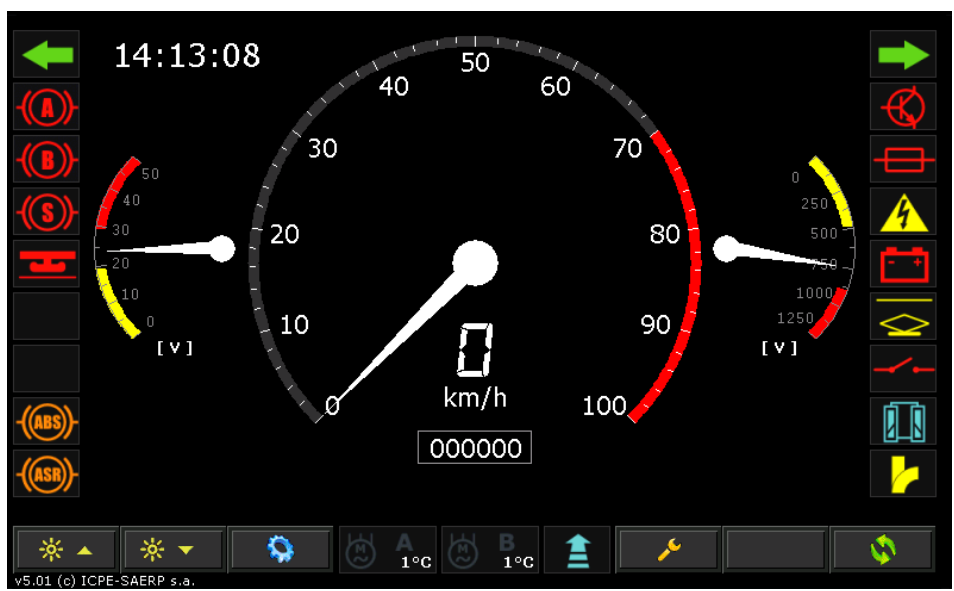

Figure 2: Front desk display.

The feedback of the commands and the on-line variables are presented on the driver's front desk on a touch-screen display (the ADT-08 is presented in figure 2).

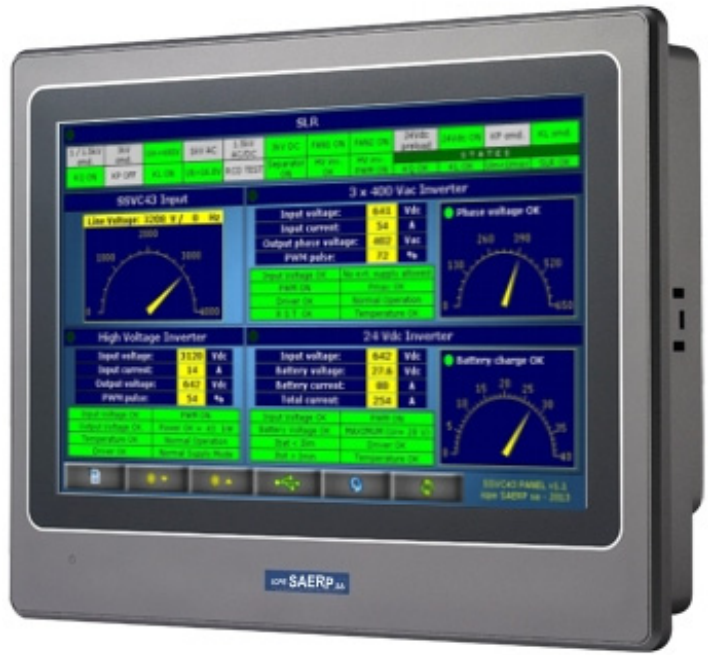

Figure 3: Display: service tab. 
Some configurations and submenus are activated by specific areas on the touch screen, thus allowing the driver or the maintenance personnel to access detailed data regarding the functioning of the vehicle.

The data regarding the energy consumption and the trip are stored inside the master unit, while the black box is stored both on the master and on the display removable memory.

\section{The on-board network of the Astra-Citelis trolleybus}

The control network of the trolleybus is based on the specification J1939 dedicated for the commercial vehicles, where there are specific frames which must be exchanged between the CAN participants. For the trolleybus application, willing to modify as few software, the traction controller SATREC-MMA was in charge of the tasks of the removed devices, such as the Diesel engine, the gear box and the retarder.

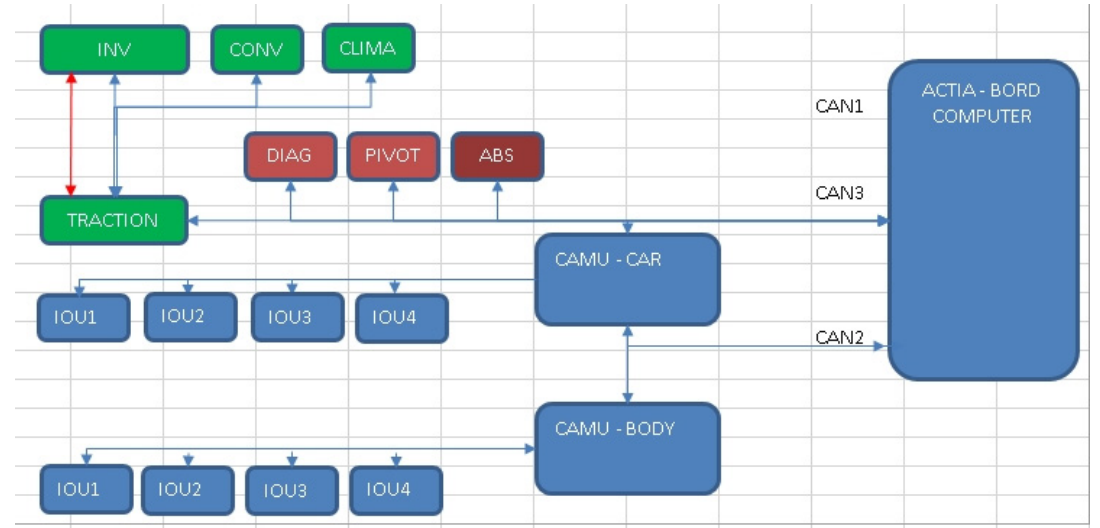

Figure 4: Trolleybus CAN network.

The data provided by the traction control unit is received by the main computer (for on-board screen), but, most important, is received by the anti-slip and anti-slide computer (ABS/ASR), the PIVOT (for the articulated vehicle), thus being able to override the traction prescribed effort in special occasions with poor adherence or over-turn.

On the same diagram the serial connections of the traction electronics can be seen, one red for the traction inverter control, and one blue for the traction converters diagnosis.

\section{The control network of the SAERP tram}

Additionally, from the control network of the trolleybus, the tram network has some notable differences: 

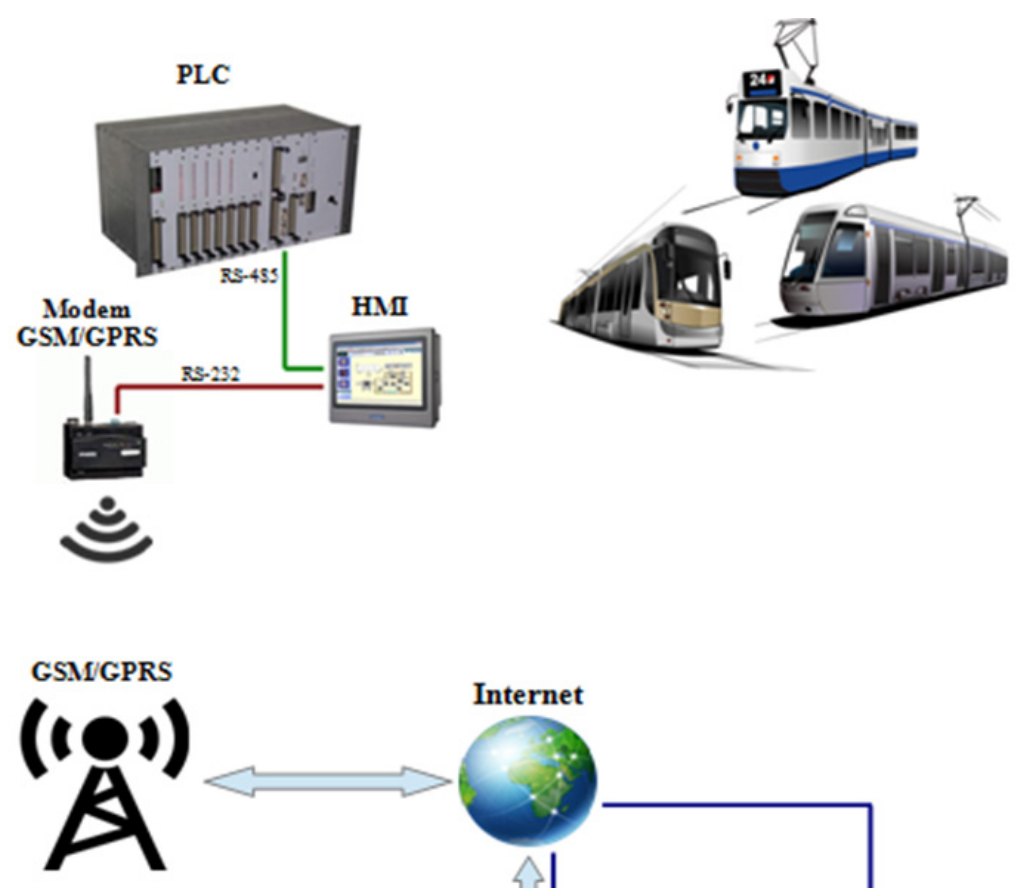

\section{Internet}
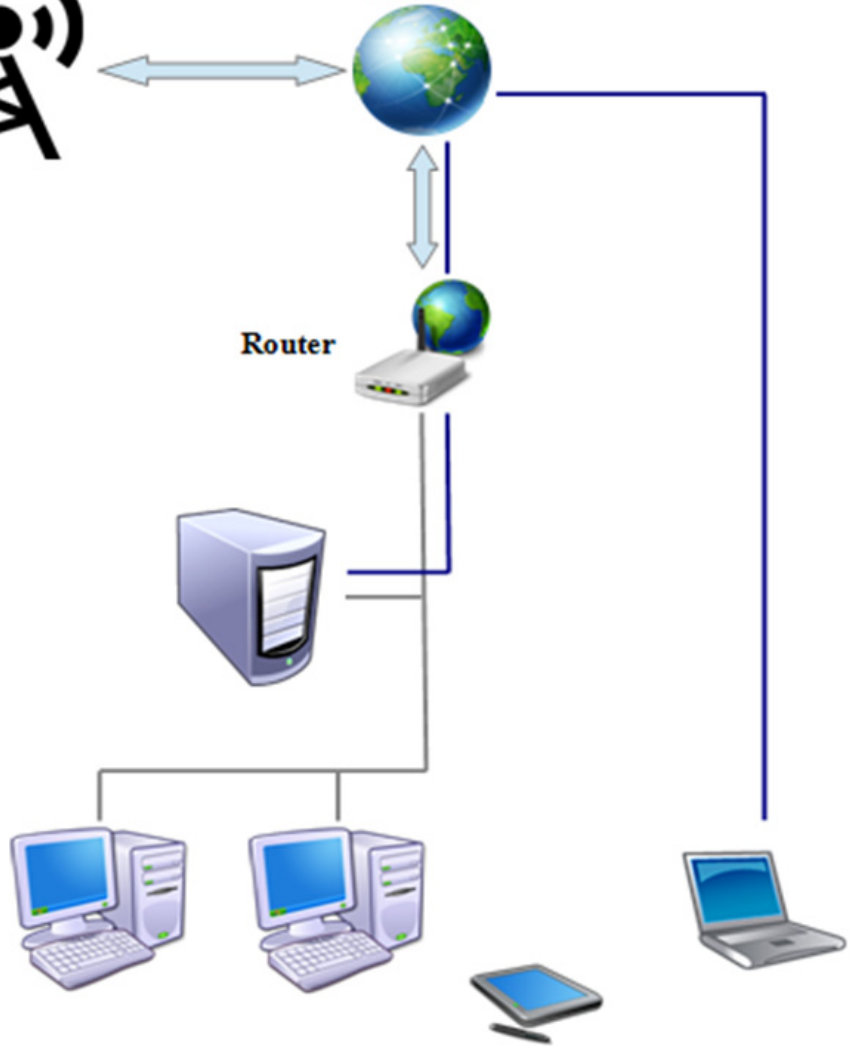

Figure 5: SCADA system. 
- The missing J1939 CAN communication channel, as the tram control systems are independent at serial level;

- Two or more traction inverters type IVF are installed and more serial operated devices are connected;

- A remote diagnosis is installed, by using a GSM/GPRS modem connected to the display ADT- 08 .

The tram is equipped with a remote monitoring system (EMS) using GSM/GPRS and Internet connections. The EMS uses the current data transfer infrastructure and allows real-time monitoring of analog information (voltage, current, temperature, speed, braking distance, mileage) and digital information (door status, brake status, door alarms, brake alarms, brake system, handle position). The secured access to the EMS is done anywhere there is an Internet connection available. The system has a user-friendly graphic interface, adaptable and easy to configure according to the monitored equipment. The parameters are available online through graphic reports and tables.

Clients connect to the server through LAN or WLAN Internet connection.

Abbreviations: RTU - Remote Terminal Units;

PLC - Programmable Logic Controller;

HMI - Human Machine Interface;

GSM - Global System for Mobile Communications;

GPRS - General Packet Radio Service;

LAN - Local Area Network;

WLAN - Wireless Local Area Network

EMS with the following functional components:

- GSM/GPRS modem (with interchangeable SIM card)

- Server and data management software, with graphic interface for online equipment monitoring.

GSM - Global System for Mobile Communications

GPRS - General Packet Radio Service

SIM - Subscriber Identification Module

\section{Human - machine interface}

The service is performed on the same display, but with a different layout. More data is displayed, as being necessary for maintenance, service and fault analysis.

The data displayed contains:

- Analog information: speed, voltage, current;

- Battery voltage;

- Braking distance;

- Status of the drivers commands;

- Status of the brakes, contactors, thermal protections;

- Inverters status. 


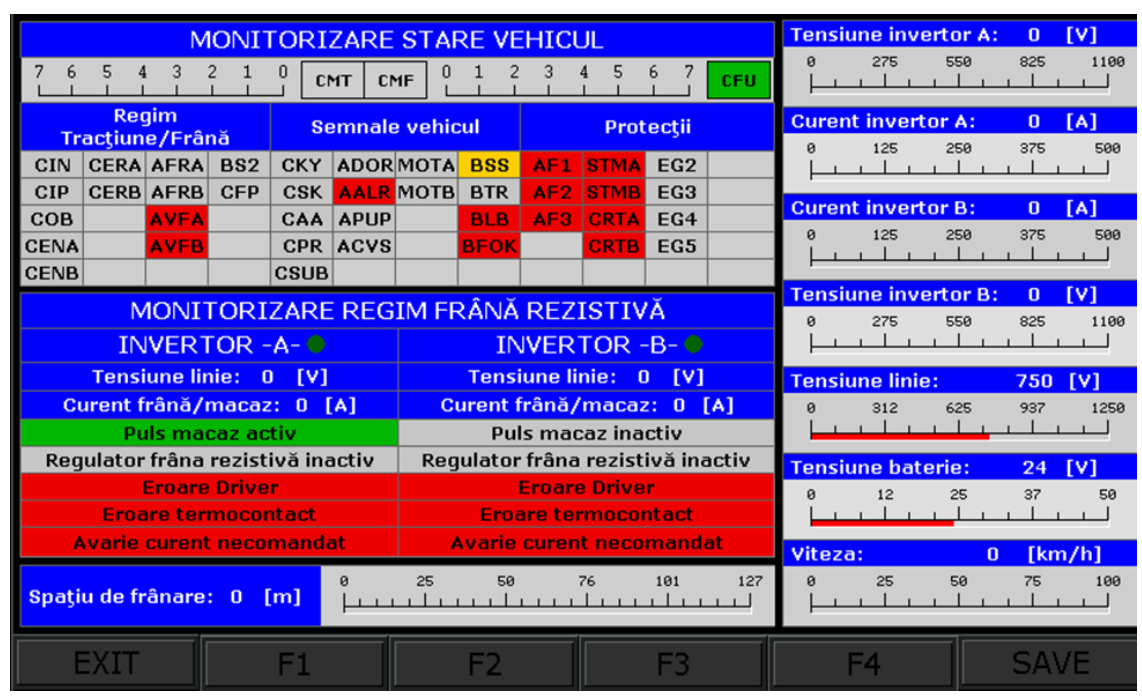

Figure 6: Human interface - tram.

\section{The advantages of the integration of the tractions equipment into the vehicle network}

Using a diagnosis system for the electric vehicle is mandatory for modern vehicles.

The main benefit is addressing the driver's work. The driver is well informed; can select the needed information as: speed, voltage, load, brake status, energy consumption and regeneration, and also can receive help.

Tasks, such as on-line diagnosis can allow remote observation of the driving behaviors and of the faults.

Emergency data can be carried out in case of attack, accident or general error. In those cases, the amount of transmitted data is enough to improve the intervention.

The electronic control systems can record a large amount of data, useful when analyzing the vehicles and the driver's operation (black-box records).

Interconnection between various systems by using serial links is reducing the cable harness on the vehicle, and allows the system to work in a unitary manner.

\section{References}

[1] B. Friman, T. Andreiouk., Automated system testing of an automatic train protection system. Proc. of the $12^{\text {th }}$ Int. Conf. on Computers in Railways, 2010, p. 71.

[2] B. Sandblad, A.W. Andersson, A. Kauppi, G. Isaksson-Lutteman, Development and implementation of new principles and system for train traffic control in Sweden, Proc. of the $12^{\text {th }}$ Int. Conf. on Computers in Railways, 2010, p. 441. 